\title{
The Effect of the Concentration of the Nutrient Solution on the Growth of Barley and Wheat in Water Cultures.
}

\author{
BY \\ WINIFRED E. BRENCHLEY, D.SC., \\ Lawes Agricultural Trust, Rothamsted.
}

With Plate II and four Diagrams in the Text.

F OR some years past much discussion has taken place as to whether the concentration of the nutrient solution has any appreciable effect upon plant growth, and at the present time the controversy is far from settled.

Brezeale ${ }^{1}$ carried out numerous water-culture experiments with wheat, using the transpiration as the criterion of growth. He states that 'it is evident that there is an optimum physical concentration of the nutritive solution at which water cultures of wheat thrive best, aside from variation in the amounts present of the different nutrient materials '. Cameron ${ }^{2}$ interprets these results otherwise, and claims that Brezeale has shown that, ' in water-culture experiments with wheat, if a given ratio of mineral nutrients be maintained, relatively small effect is produced on the growing plants by varying the concentration over a wide range, in one case 75 parts per million to $75^{\circ}$ parts per million, and this effect seems to be largely independent of the nature of the particular mixture of solutes'.

Hall and Underwood, ${ }^{3}$ however, obtained indications that with barley the concentration of the nutrient solution in water culture has a definite effect upon growth, the total dry weight of the plants decreasing with the strength of the solution. Recently Stiles ${ }^{4}$ has made further inquiry into the matter and states that 'the variation over a fairly wide range of the concentration of the nutrient solution of ryc and barley growing in water cultures produces relatively little effect on the amounts of dry matter produced. Below a certain concentration there appears to be a definite falling off in the rate of growth.'

When the figures given by Stiles for the dry weights of barley in

1 Brezeale, J. F.: Effect of the Concentration of the Nutrient Solation upon Wheat Cultures. Science, $\times x$ ii, Pp. $146-9$ (1905).

2 Cameron, F. K. : The Soil Solution, pp. 40-1.

- Hall, A. D., Brenchley, W. E., and Underwood, L. E. : The Soil Solution and the Mineral Constituents of the Soil. Phil. Trans. Roy. Soc. 204, B 307 (1913).

- Stiles, W.: On the Relation between the Concentration of the Nutrient Solution and the Rate of Growth of Plants in Water Cultures. Ann. Bot., vol. xxix (1915).

[Annals of Botan Y, Vol. XXX. No. CXVII. Janaary, ig16.] 


\section{Brenchley.-Effect of Concentration of the Nutrient Solution}

water cultures are compared with those for thousands of plants grown at Rothansted during the last nine years, it is seen that they are remarkably low, so low as to suggest that some factor was in action at Leeds that was quite ignored or overlooked in the estimation of results. Plants are very sensitive to external influences other than those of food and water-supply, and the amount of light, variations of temperature, and the atmospheric conditions prevailing during the growing period all have definite action on the rate and quality of growth. Crowther and Ruston ${ }^{1}$ have shown that the smoke pollution of the air at Leeds is so great that plant life is most seriously affected, considerable depression in growth being caused at the University. This factor must have operated upon the water cultures, and may, to some extent at least, have vitiated the results obtained. Whereas at Leeds in 1914 the mean dry weight of barley-plants grown from April 28 to June 6 was only $0.628 \mathrm{grm}$, at Rothamsted one series grown simultaneously from April 27 to June 9 averaged $2.5 \mathrm{I} 6 \mathrm{grm}$. dry weight, another series averaging $2.252 \mathrm{grm}$., and this was in spite of the advantage gained by the Leeds plants in the frequent renewal of food solution, while the Rothamsted plants remained in the initial solution all through the experiment.

It has been stated that 'plants growing in water cultures under exactly the same conditions are very variable ', ${ }^{2}$ and this is used as an argument for discounting the value of water cultures as a method of experiment. ${ }^{3}$ As a matter of fact, the individual variation of plants within a single series is far less than with similar plants growing under natural conditions in the open field. It is only necessary to examine carefully a small area of barley in the field, plant by plant, and to compare with a number of water cultures growing at the same time, in order to be convinced of the truth of this fact. Dactylis glomerata is on the whole a bad subject for water-culture experiments, but even in this case the range of individual variation under such conditions is most obviously less than between plants growing on the experimental plots. Mean variation from series to series is fairly great, because the period of the year has a very great influencc upon the rate of growth, and plants grown in January and February may possibly not reach one-quarter the development (as shown by dry weight) of similar plants grown in April and May for the same length of time. Experiments have shown that the difference of even a week in putting plants in water cultures has a distinct effect upon the total dry matter that can be produced within a given time. Every experimental method has its disadvantages and its weaknesses, and while water-culture methods are far from perfect, and indeed make no claim to be so, yet they do afford those conditions that are the most under the control

1 Crowther and Ruston: Town Smoke and Plant Growth. Joum. Ag. Sci., vol. vi, Pt. iv, pp. $387-94$.

2 Stiles, W. : loc. cit., p. 89 .

S Stiles and Jorgensen : Studies in Permeability, 1. Ann, Bot., rol. xxix, p. 349 (19 I5). 
of the operator, and for that reason, if for no other, they have a special value of their own.

During the season of I 15 a number of water-culture experiments have been made to see if further light could be obtained as to the effect of varying concentrations of nutrient solutions upon growth, barley being used as the test plant in the three main series, wheat being grown in one case only. Four strengths of nutrient salts were used, N, N/5, N/10, N/20, the $\mathrm{N}$-solution being that in general use in the laboratory, containing-

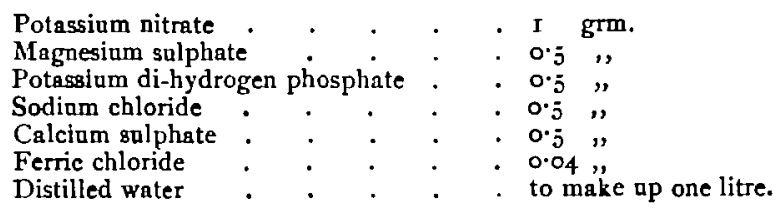

The range of concentration was thus approximately $3, \infty 00,600,300$, I 50 parts of food-salts per million, containing potassium, phosphate, and nitrogen as in the following table:

$\begin{array}{cc}\text { Parts per } & \\ \text { million of } & \mathrm{N} \\ \mathrm{K}, \mathrm{O} & 640 \\ \mathrm{P}_{3} \mathrm{O}_{5} & 204 \\ \mathrm{~N} & 13^{8}\end{array}$

$\begin{array}{ccc}\begin{array}{c}\text { Concentration of } \\ \text { Solution }\end{array} & \\ \text { N/5 } & \text { N/10 } & N / 20 \\ 128 & 64 & 32 \\ 41 & 20.5 & 10.25 \\ 28 & 14 & 7\end{array}$

All the usual precautions were taken; the bottles were thoroughly washed, new corks were used in every case, the water was obtained from a silver still which was kept scrupulously clean and polished, and the foodsalts were uniform all through the experiments and were weighed up separately for each unit of ten plants. ${ }^{1}$ The barley was a pure strain of 'Plumage' obtained from Mr. Beaven, and the seeds were all graded between 0.05 and $0.06 \mathrm{grm}$. to reduce individuality as much as possible. The wheat was a pure line of 'Persian' wheat obtained through the kindness of Dr. N. Vavilov of Moscow; these seeds had to be sown without grading, as the supply was very limited.

In each experiment with barley 120 plants were grown in units of ten.

(I) All concentrations $(\mathrm{N}, \mathrm{N} / 5, \mathrm{~N} / \mathrm{rO}, \mathrm{N} / 20)$, the solutions being changed regularly every four days.

(2) All concentrations, the solutions being changed once, exactly halfway through the experiment.

(3) All concentrations, the solutions being never changed.

Great care was taken of the roots when the solutions were being changed. While the bottles were refilled, one by one, the plants were removed, and the roots laid in a saucer containing a little solution corre-

1 The salts used were Kahlbanm's 'for analysis', and the stock was specially reserved for this experiment in view of the impossibility of replacing them at the present time. 
sponding in strength to that from which the plant was taken, so that no check was caused, either by slight desiccation or by shock from the roots being laid in pure water or in an alien solution. Each test ran for seven weeks, and was repeated three times at intervals of three weeks, so that information was obtained for plants grown early and late in the season. The developmental history was carefully noted, and it was found that the difference in growth of plants in different concentrations was not only shown by the ultimatc dry weights. but was apparent to the eye through the whole course of the experiments, both with regard to the size of plants and type of growth, especially with the roots. Each plant was harvested separately, and the dry weights of roots and shoots recorded.

\section{First Series.}

Seeds sown, March 5 .

Plants put into solutions, March $\mathrm{I}_{5}$.

Plants harvested, May 3.

Solutions changed 'frequently', at regular intervals of four days.

Solutions changed 'once', on April 8.

Solutions frequently changed. Most of the plants started off with fairly normal root growth, but the $\mathrm{N} / 20^{1}$ began to vary within the first few days, remaining short, with short thin laterals, which gave the roots a square bunchy appearance compared to the usual long type. This 'bunchiness' persisted for several weeks, but eventually the laterals elongated more normally. An unusual feature of the root growth was seen in all concentrations at the end of about a month. In addition to the usual thin roots supplied with long thin laterals, there appeared a number of very thick long rootlets springing from the base of the plant, either entirely free from laterals or else furnished with a very few tiny ones. These rootlets were thickest and most numerous in the $\mathrm{N}$-plants and persisted to the end, so that at harvest-time the roots were inclined to be thick and much less fibrous than usual. In the lower concentrations these roots were very prominent at the time of formation, but were overshadowed later on by the further development of fibrous rootlets, and at harvest the roots had regained a more normal type.

The development of the shoots in the plants growing in the different concentrations was very similar for some long time, but gradually a falling off was noticed with the two lowest $(\mathrm{N} / 10, \mathrm{~N} / 2 \mathrm{O})$, and by harvest-time some indications of this appeared even with $\mathrm{N} / 5$ shoots. In the $\mathrm{N}$-plants the shoots were of an exceptionally dark green colour to the very end, the lowest leaves remained green and healthy, and there was no sign of red coloration at the base of the stem. The $\mathrm{N} / 5$-plants showed similar

1 For convenience of reference, the plants in the different concentrations will be called $N, N / 5$, N/10, N/20 plants. 
development, and were nearly as dark in colour when harvested, but some of the lowest leaves had begun to turn yellow, and a trace of red was visible in the stem a few days before cutting. In N/ro-plants these phenomena were more marked. The withering of the lower leaves and coloration of the stem had set in at an earlier date and were more pronounced, also the general development was less good. With the lowest concentration $(\mathrm{N} / 20)$ the shoots were very much smaller than in any of the others, and were of a yellowish green colour, while the lowest leaves had died off a fortnight earlier, at the same time as the red colour appeared in the stems.

The general trend of these observations is reflected in the dry weights of the plants, which will be discussed later.

Solutions never changed. The difference in concentration affected root growth immediately, each strength of solution having a definite effect of its own. The N/5-roots fell behind the normal within a week, being short and rather bushy with laterals standing out from the rootlets at an angle. These laterals elongated later, and gave the roots a more typical appearance till they looked stronger than the $\mathrm{N}$, but this appearance was falsified by the dry weights. In the lower concentrations the roots were very poor at first, bunchy, with rather thick laterals standing out on every side, giving the roots a 'stark' appearance, but later on de-

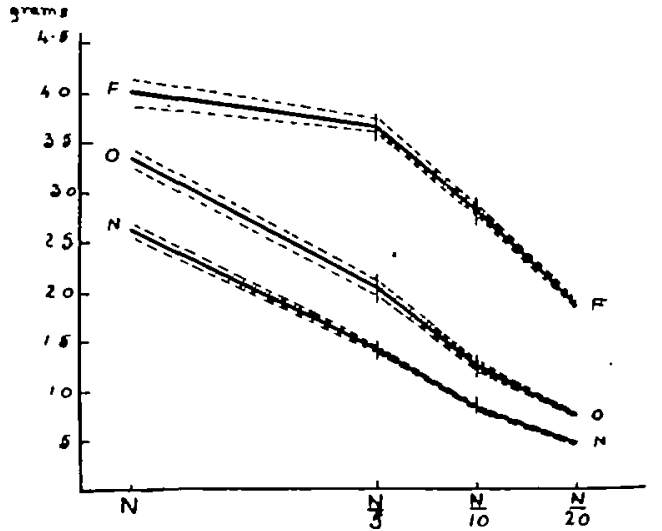

Curve r. Mean dry weights of ten barley-plants growing in nutrient solutions of different concentrations. Dotted lines show the limits of probable error. $F$, frequently changed; $O$, once changed; $N$, never changed. (March I 5 -May 3.) velopment became more normal in type, though still weak. The abnormal development of thick unbranched rootlets seen with 'frequently changed' plants was not noticed in any instance where the solution remained unchanged throughout the course of the experiment. Shoot growth showed a regular depreciation as the concentration of the nutrient solution diminished. The weaker the solution, the earlier etiolation set in, and the sooner did the lower leaves begin to die off and the red colour appear at the base of the stem. Towards the close of the experiment the difference in the amounts of water lost by transpiration was very marked, hardly any being given off by the $\mathrm{N} / 20-$ plants.

Solutions once changed. The single change of solution kept the $\mathrm{N}$-plants growing better, so that at harvest-time the plants were more strongly developed and of better colour than in the 'never changed' set. 


\section{Brenchley.-Effect of Concentration of the Nutrient Solution}

With all other concentrations the march of events was delayed, but not arrested. Considerable improvement occurred immediately after the change (the weaker the solution the more obvious the improvement), but the falling off in growth soon reasserted itself in each case, though the 'fillip' caused by the renewal of the food supply was well reflected in the dry weights (see Table I and Curve I).

Series I. March I5-May 3.

\begin{tabular}{|c|c|c|c|c|c|c|c|c|c|}
\hline \multirow{3}{*}{ Solution. } & \multicolumn{8}{|c|}{ Solutions changed } & \multirow{2}{*}{ er. } \\
\hline & \multicolumn{3}{|c|}{ Frequently. } & \multicolumn{3}{|c|}{ Oree. } & \multicolumn{2}{|c|}{$\begin{array}{l}\text { l' } \\
\text { Never. }\end{array}$} & \\
\hline & Shoot. & Root. & Total. & Shoot & Root. & Total. & Shoot. & R'oot. & Total. \\
\hline $\begin{array}{l}N \\
N / 5 \\
N / 10 \\
N / 20\end{array}$ & $\begin{array}{l}2 \cdot 9^{19} \\
2 \cdot 608 \\
1 \cdot 9^{8}+ \\
1 \cdot 303\end{array}$ & $\begin{array}{l}I \cdot 082 \\
I .041 \\
0.816 \\
0.528\end{array}$ & $\begin{array}{l}4.001 \pm 0.142 \\
3.649 \pm 0.074 \\
2.800 \pm 0.049 \\
1.831 \pm 0.038\end{array}$ & $\begin{array}{l}2.639 \\
1.483 \\
0.791 \\
0.447\end{array}$ & $\begin{array}{l}0.713 \\
0.543 \\
0.447 \\
2.289\end{array}$ & $\begin{array}{l}3.35^{2} \pm 0.096 \\
2.026 \pm 0.072 \\
1.238 \pm 0.048 \\
0.736 \pm 0.001\end{array}$ & $\begin{array}{l}1 \cdot 897 \\
0.958 \\
0.526 \\
0.244\end{array}$ & $\begin{array}{l}0.735 \\
0.446 \\
0.301 \\
0.308\end{array}$ & $\begin{array}{l}2.632 \pm 0.07 \mathrm{I} \\
1.404 \pm 0.020 \\
0.827 \pm 0.015 \\
0.452 \pm 0.011\end{array}$ \\
\hline
\end{tabular}

Series 2. April 5-May 24.

\begin{tabular}{|c|c|c|c|c|c|c|c|c|c|}
\hline \multirow{3}{*}{ Solntion. } & \multicolumn{8}{|c|}{ Solutions changed } & \\
\hline & \multicolumn{3}{|c|}{ Frequently. } & \multicolumn{3}{|c|}{ once. } & \multicolumn{3}{|c|}{ Never. } \\
\hline & Shoot. & Root. & Total. & Shoot. & hoot. & Tolal. & Shoot. & Root. & Tolal. \\
\hline $\begin{array}{l}N \\
N / 5 \\
N / 10 \\
N / 20\end{array}$ & $\begin{array}{l}4.442 \\
3 \cdot 365 \\
1.899 \\
1.283\end{array}$ & $\begin{array}{l}1.330 \\
1.137 \\
0.843 \\
0.683\end{array}$ & $\begin{array}{l}5.77^{2} \pm 0.193 \\
4.502 \pm 0.076 \\
2.74^{2} \pm 0.097 \\
1.966 \pm 0.042\end{array}$ & $\begin{array}{l}3.746 \\
1.621 \\
0.841 \\
0.363\end{array}$ & $\begin{array}{l}1.324 \\
0.709 \\
0.470 \\
0.318\end{array}$ & $\begin{array}{l}5.070 \pm 0.209 \\
2.330 \pm 0.117 \\
1.311 \pm 0.056 \\
0.681 \pm 0.025\end{array}$ & $\begin{array}{l}3 \cdot 048 \\
1 \cdot 136 \\
0.525 \\
0.253\end{array}$ & $\begin{array}{l}1.159 \\
0.631 \\
0.409 \\
0.258\end{array}$ & $\begin{array}{l}4.207 \pm c .113 \\
1.567 \pm 0.037 \\
0.934 \pm 0.240 \\
0.511 \pm 0.015\end{array}$ \\
\hline
\end{tabular}

Series 3. April 26-Junc I4.

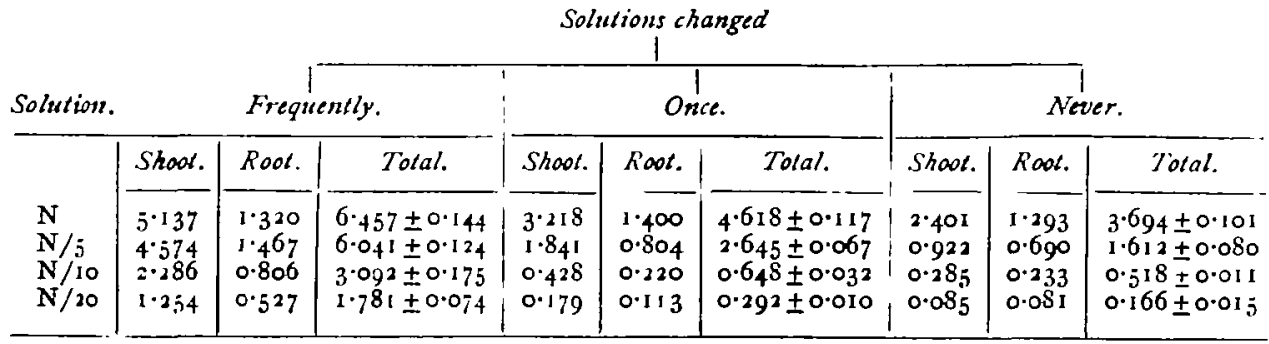

Table I. Mean dry weights in grams of ten barley-plants grown in nutrient solutions of various strengths, 


\section{Second Series.}

Seeds sown, March 27.

Plants put in solutions, April 5 .

Plants harvested, May 24 (Plate II, Figs. I, 2, 3).

Solutions changed 'frequently', at intervals of four days.

Solutions changed 'once', on April 30.

The course of events was the same as in the first series, though growth was more rapid owing to the more favourable season for growth, and differences due to the varying concentrations were more marked than in the earlier experiment (Curve 2). The thick rootlets in 'frequently changed' plants were less strongly developed. It seems probable that the frequent renewal of the nutrient salts caused the plants to put out the abnormal rootlets for some unexplained reason, particularly at the time of year when growth was fairly slow. When growth was more rapid, the root development remained more normal in type, though thick rootlets did appear to some extent. Later on in the year they were only produced by plants in high concentrations, the others bearing quite normal fibrous roots. It may very tentatively be suggested that the thickened rootlets provide a means of protection at certain periods of growth against the constant change of balance due to the frequent renewal of the food solution. As they are so badly provided with laterals, it may be that they are able to prevent the ingress of too great and sudden an influx of food material at the time of the change of solution, so that they act as a kind of control. When growth is more rapid, the plant can deal with extra food more readily, so that the controlling function is of less impor-

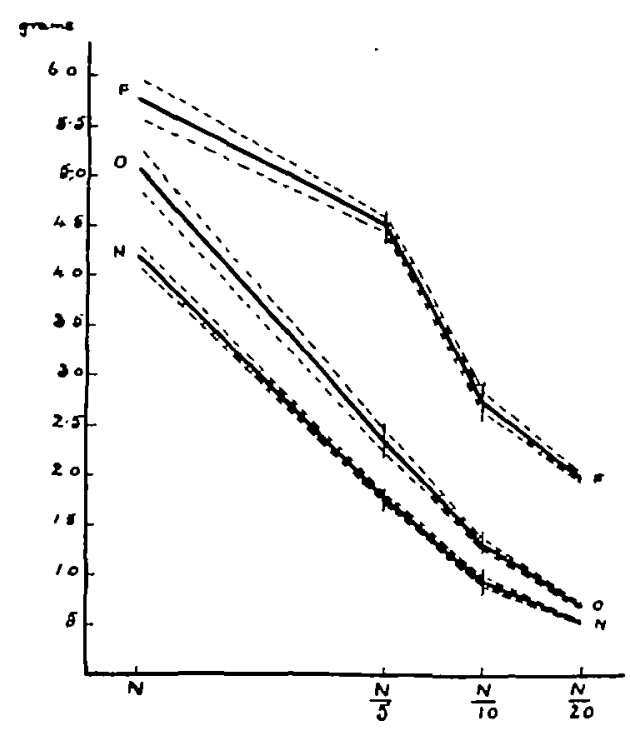

Curve 2. Mean dry peights of ten barley-plants growing in nutrient solutions of different concentrations. Dotted lines show limits of probable error. (April 5-May 24.) tance, and the thick roots are correspondingly less developed. This idea is also borne out by the fact that in the first series the $\mathrm{N}$-plants produced very thick rootlets in quantity, rendering the root thick and much less fibrous than usual, thus indicating possibly that at that time of year the plant was never able fully to cope with such a constant renewal of food solution of high concentration, owing to the relative slowness of growth which entailed the utilization of a lesser quantity of plant food (see Table I). 
Seeds sown, April $\mathbf{6} 6$.

\section{Third Series.}

Plants put into solutions, April 26.

Plants harvested, June $\mathrm{I} 4$.

Solutions changed 'frequently', every four days.

Solutions changed 'once', May 20.

This series was started rather late in the season, so that in some ways the plants exhibited more variability than in the earlier experiments. With

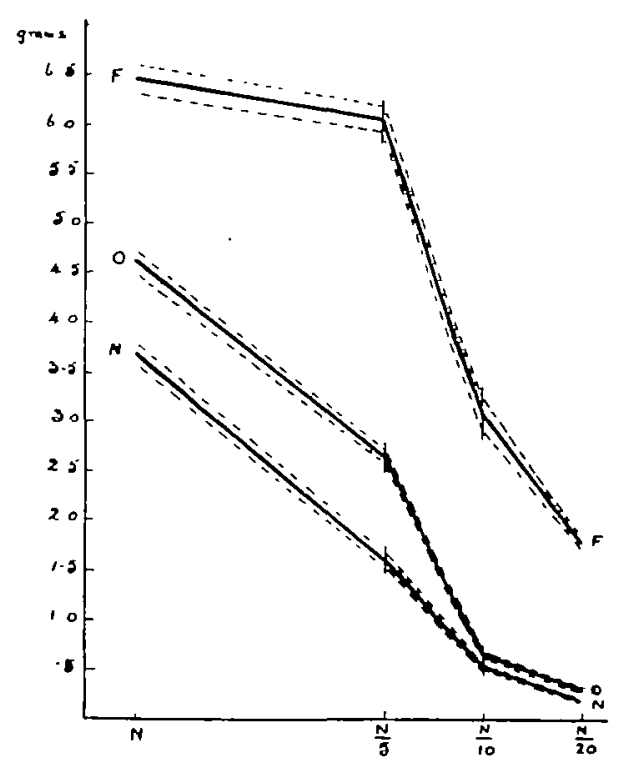

CURVE 3. Mean dry weights of ten barley-plants grown in nutrient solntions of different concentrations. Dotted lines show limits of probable error. (April 26-June I4.) frequently changed solutions the life-histories were much as usual ; in the $\mathrm{N}$-plants the roots were inclined to be rather short and bushy from first to last, and were well supplied with the typical thick rootlets; for about a month the $\mathrm{N} / 5$-plants looked stronger than the $\mathrm{N}$, but this did not continue; in lower concentrations a rapid falling off of growth was exhibited. The red coloration did not appear in the stems, but the lower leaves were dead in every case. When the solutions were rarely or never changed, the plants in the two lower concentrations made little or no headway for a long time. Root development was checked almost entirely for three or four weeks,

after which very long thin roots were produced. The shoots were also long and very thin, with little or no tillering. The sharp falling off in growth below the $\mathrm{N} / 5$ concentration, even when the solutions were changed, is well shown in the graph (Curve 3 and Table I).

\section{DISCUSSION OF RESULTS.}

An examination of the figures and curves of dry weight in all three series shows that, however the solutions are treated, there is a steady decrease in the dry weights of the plants as the strength of the nutrient solution gets less. This decrease in weight is very considerable and is always outside the limits of experimental error. The results run in the same direction in all the experiments, the differences being accentuated in the sets grown later in the year, when growth is more rapid. It is noticeable that the drop in dry weight from $\mathrm{N}$ to $\mathrm{N} / 5$ is far less when the solutions are changed frequently, 
and in some cases (Series $I$ and 3 ) the approximation is fairly close. This suggests the possibility that more frequent renewal of the solutions, maintaining more evenly the balance of the nutrient salts, would be followed by as much growth in the $\mathrm{N} / 5$ as in the $\mathrm{N}$ concentration, although the tendency is for growth to fall behind in the lower strength with small provocation. In other words, if it were possible to arrange an experiment in which the balance of the nutrient solution was kept constant by the automatic replacement of the food-salts absorbed, it is conceivable that plants in these two concentrations might produce equal quantities of dry matter. But there are indications that toxic effects would set in under these circumstances in the $\mathrm{N}$ solution, as some of the constituents might be present in so great a quantity as actually to put a brake on plant growth. In the $\mathrm{N} / 5$ solution, on the other hand, the probability of such action is considerably less, and the plants would continue to make full use of the food-salts and would approximate in growth to those in the $\mathrm{N}$ solution. If this supposition be correct it is not true to say that the plant is indifferent to the variation in the strength of these two solutions, but that it responds to increased strength by increased growth. With the highest concentration, $N$, however, another factor, that of toxic action, comes into play, counterbalancing the increased growth and reducing it to the level of that attained with the lower $(\mathrm{N} / 5)$ concentration. Further experiments are being made to obtain more definite information on this point, and also to find out whether there is an optimum concentration for growth or whether the plant will grow equally well within a certain range of the higher concentrations. The main point at issue at present is not that of equal growth in varying concentrations, but that of the great dilution at which it is claimed that such equal growth can be made. With concentrations below $\mathrm{N} / 5$ a very different result is obtained. The more frequently the solutions are changed, i.e. the closer the concentrations approach to a state of constant balance, the more marked is the drop in the dry weights as the strength of the solution decreases. This implies that with the lower strengths the plant is living in a condition of semi-starvation. When the solutions are changed frequently, the improvement of growth is the more marked the higher the concentration (up to a certain limit, $\mathrm{N} / 5$ in this experiment), owing to the sum total of food supplied approximating more closely to the needs of the plant for optimum growth. It is difficult to imagine that, even if a constant balance of foodsalts could be maintained, the plants in the solutions below N/5 would in any way approach those in the higher strengths, as, if this were indeed the truth, some indications of it would have been obtained by some incipient approximation of dry weights, such as occurred with plants in $\mathrm{N}$ and $\mathrm{N} / 5$ solutions, instead of a marked and decreasing divergence of these weights as the concentrations rose towards $\mathrm{N} / 5$, when solutions were frequently renewed. As a matter of fact, the actual dry weights of the $\mathrm{N} / 10$ 
and $\mathrm{N} / 20$ plants in frequently renewed solutions were practically the same, within the limits of error, in all three experiments, showing that the same amount of growth had taken place in each case, whereas normally plants grown later in the season form much more dry matter, owing to the increase in the rate of growth, the $\mathrm{N}$ and $\mathrm{N} / 5$ plants in the three series being about 50 per cent. heavier than those in the first series grown seven weeks earlier.

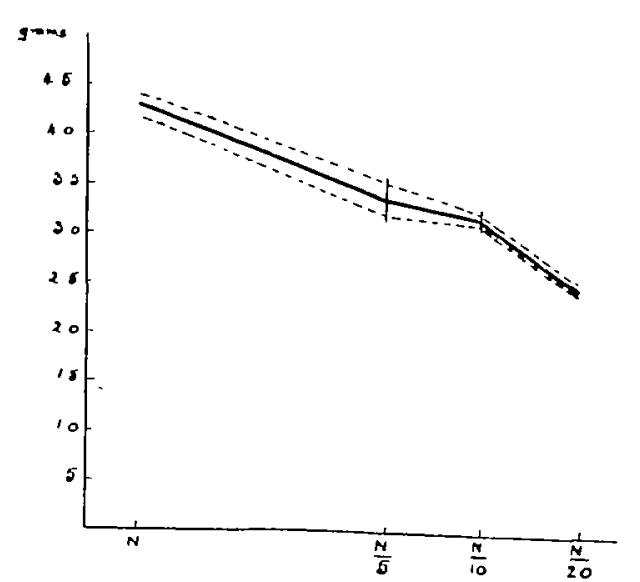

Curve 4. Mean dry weights of six wheat-plants grown in nutrient solutions of different concentrations. Dotted lines show limits of probable error. Solutions frequently renewed. (Marctr 16-May i I.)

This indicates that with the lower strengths the amount of growth was strictly limited by the quantity of food supplied, and that it was impossible for the plants to reach full development with such a restricted amount.

In the single solution with wheat, the solution was frequently changed, and the plants were grown on for eight weeks. In this case again, a steady fall in dry weight occurred with decrease of concentration, but owing to lack of seeds it was not possible to carry the comparison so far as with barley. The drop is less marked with wheat, but this may

be because it grows more slowly than barley, so that differences are less accentuated within the same limits of time, though they are none the less definitely marked (Curve 4 and Plate II, Fig. 4).

Before proceeding to discuss the significance of these results further, it may be useful to summarize the effect of varying concentration of foodsalts obtained by different workers.

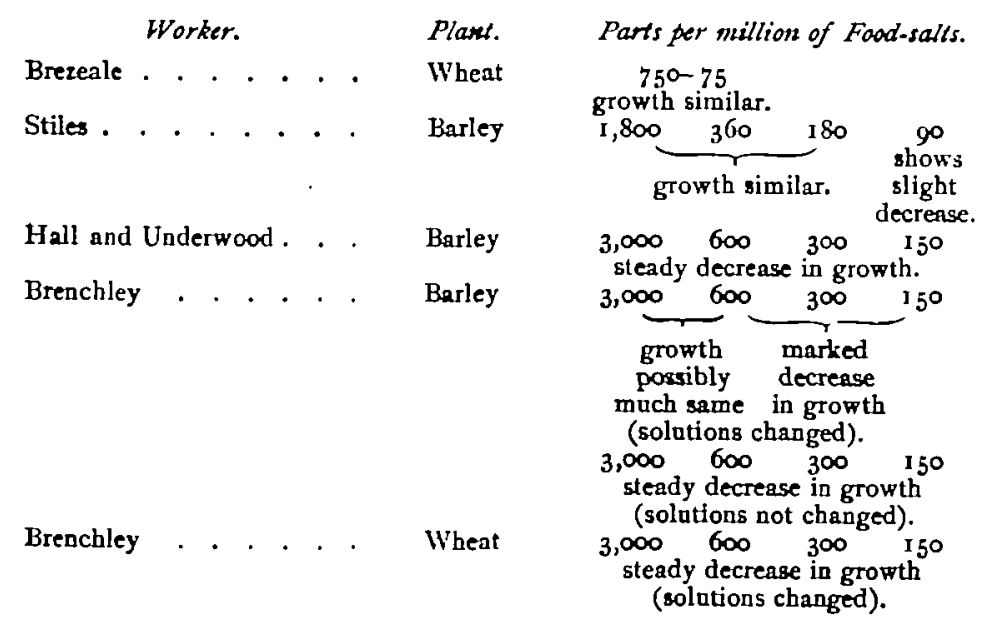




\section{on the Growth of Barley and What in Water Cultures. 87}

The above table shows how great are the discrepancies between the results of several workers dealing with the same species by the same method of water-culture experiments. In the explicit statement by Cameron quoted earlier, it is claimed that the effect of the varying concentrations is largely independent of the particular mixture of solutes. If this statement be true, it matters little what nutrient solution is used, provided plants will make good growth in it, and the argument cannot be advanced that the difference in composition of the solution explains the discrepancies between the results, concentration being the only point at issue, provided that balance or a given ratio of nutrient salts be maintained as far as possible. Stiles ${ }^{1}$ probably came very close to the truth in saying that 'possibly in the American experiments something other than concentration of salts was acting as a limiting factor in all cases', but apparently he failed to see that the same remark may have had a very pertinent bearing upon his own results, owing possibly to the smoke factor in the Leeds district. Brezeale found with wheat that about 300 parts per million of food-salts gave maximum growth, and that growth fell off as the concentration increased to $75^{\circ}$ parts per million or decreased to 75 parts per million, whereas at Rothamsted wheat shows a steady depreciation of growth as the concentration decreases from 600 to 150 , well within the former range. Stiles maintains that barley grows equally well within the range of $I, 800$ to I 80 pts. per. mil., and only shows a slight depression with as little as 90 pts. per. mil., whereas at Rothamsted a great and marked decrease in growth occurs from 600 to I 50 pts. per. mil. It seems more than probable that some depressing factor must have been at work in the Leeds experiments, which tended to equalize the growth of the plants by hindering them in some way which prevented normal development and reduced growth to a dead level. Such a factor might be provided by the presence of minute quantities of a toxic body in the distilled water or in the salts used for making up nutrient solutions. Experience has shown that the presence of the merest traces of copper salts in differential experiments will vitiate growth to such an extent as to make comparison useless, and unless the water is prepared with the utmost care such toxic substances find only too easy an entrance. Unfavourable atmospheric conditions, unsuitable temperature, lack of cleanliness in working, growth of algae in culture bottles, and the admittance of light to the roots are a few of the factors which may adversely affect growth, and which have to be taken into consideration in estimating results if they come into play. It is impossible to generalize from water cultures to sand or soil cultures, or from one species to another, but so far as the growth of barley and wheat in water cultures is concerned, this last experiment at Rothamsted upholds the earlier contention of Hall and Underwood that the concentration of the nutrient solution influences very

1 Stiles, W. : Review, Journ. Ecol., vol. it, p. 54 (1914). 


\section{Brenchley.-Effect of Concentration of the Nutrient Solution}

greatly the rate of growth of plants. Not only is the rate of growth affected, but the amount of growth is strictly limited by the quantity of available food when the nutrient solutions are dilute. Little work has yet been done with higher concentrations, but it is possible (see page 85 ) that toxic action due to over-nutrition from too great a supply of food-salts comes in to counterbalance or replace the increase of growth caused by increase of nutriment which occurs with lower strengths.

Although the experiments fail to corroborate the idea that concentration is unimportant within very wide limits, still they fully support other observations made by Stiles. In every case there is a drop in the dry weight of plants grown in any concentration-according to the frequency with which the solutions arc changed, the 'frequently changed' plants being heavier than the 'once changed', and the 'once changed' than the 'never changed '. With the normal strength it is probable that there is a sufficient supply of food material even when no renewal of solution takes place. In one case, barley was grown in such a normal solution for over eight weeks, and analyses made at the end of the experiment showed that 25 per cent. of the initial nitrogen still remained in the solution, and as the nitrogen compounds are absorbed in greater quantities than other salts it is evident that an ample sufficiency remained, if the quantity of the salts were the only factor concerned. Thus it is probable that with this concentration the question of starvation does not arise, and that the steady decrease in weight is really associated with the change of balance of the nutrient salts, the plants being the better the closer the initial balance is maintained.

With the lower concentrations, the drop in weight from 'frequently changed' plants to the others was much heavier. Since with the normal solution the decrease in weight due to the balance of the food-salts was so much less marked, it seems permissible to assume that the very heavy drop with the lower concentrations is due largely to quite another cause, that of varying degrees of starvation through lack of sufficient nutriment. When the solutions are changed as often as once in four days, twelve times altogether, the plant has access during its lifetime to a far greater store of food material than when solutions are seldom or never changed. Consequently such plants suffer less from the starving effects due to the low concentrations of the food-salts in solution, but still the response corresponds strictly to the amount of food available at any one time. Therefore it seems evident that with the normal solution the change in the balance of food-salts has a hindering action upon the growth of barley, and that this hindrance is coupled with varying degrees of starvation as the concentration decreases, being specially accentuated in those cases in which the solution is never changed.

It has frequently been noted that the variation in the strength of the food solution not only affects the total dry weight of the plant, but 


\section{on the Growth of Barley and Wheat in Water Cultures. 89}

also has a very marked action upon the relative rate of growth of roots and shoots, and this is well shown in the experiments under discussion. All the way through, the shoot responds more sharply than the root to the changes in food supply; consequently, as the solution decreases in strength the ratio between the dry weights of shoots and roots also decreases; in other words, the weights of the roots and shoots tend to approximate more closely as the supply of nutriment gets smaller, until in some cases with very dilute solutions the root is as heavy as, or even heavier than, the shoot (Table II). The change in ratio takes place always, whether the solutions are changed or not during growth, but it is most marked in those cases in which great starvation has ensued owing to the low concentrations not being renewed. It seems as though the plant makes every endeavour to supply itself with adequate nutriment, and as if, when the food supply is low, it strives to make as much root growth as possible so as to offer the greatest absorbing surface for whatever nutriment may be available.

\section{Shoot/Root Ratio.}

Series I. March I5-May 3 .

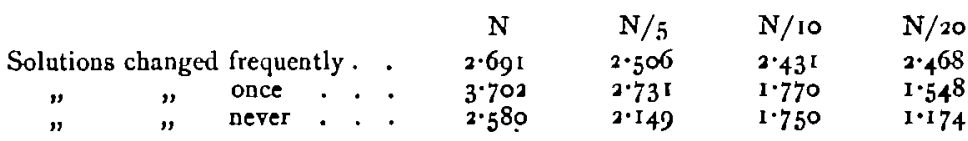

Series 2. April 5-May 24.

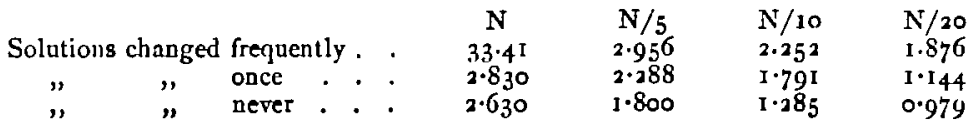

Series 3. April 26-June I4.

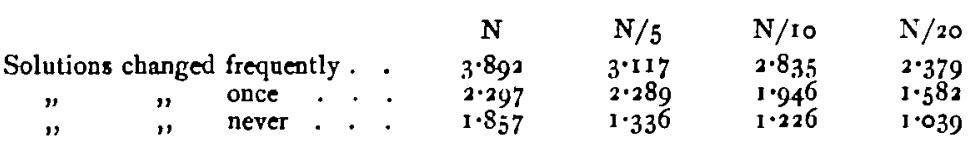

Table II. Showing the ratio between the shoots and roots of the barley-plants whose mean dry weights are given in Table $\mathbf{I}$.

\section{SUMMARY.}

When plants, such as barley and wheat, are grown in water cultures under favourable conditions, the concentration of the nutrient solution, up to a comparatively high strength, has a great effect upon the rate and amount of growth, even when the balance of the solution approximates to a constant level. Starvation effects, due to insufficient nutriment, are evident in much stronger concentrations than has been admitted by some 
other observers. The action of different high concentrations of constant balance has not yet been determined, and it is uncertain whether there is an optimum strength, above and below which growth falls off, or whether there is a range of concentrations between which the plants will make equally good growth. It seems evident, however, that if water cultures with wheat and barley are carried out under advantageous growthconditions, complete and maximum growth cannot be obtained in a solution containing the amount of potash and phosphoric acid $\left(\mathrm{K}_{2} \mathrm{O}\right.$ 28 p.p.m., $\mathrm{P}_{2} \mathrm{O}_{5} 7$ p.p.m.) stated by Cameron to exist in the soil solution.

1 Rothamsted, Oclober, 1915 .

\section{EXPLANATION OF PLATE II.}

Illustrating Dr. Brenchley's paper on Concentration of Waler Cullures.

Fig. I. Photograph showing the growth of barley-plants in water cultures when solutiong were frequently renewed. Concentration of solutions, $\mathrm{N}, \mathrm{N} / 5, \mathrm{~N} / 10, \mathrm{~N} / 20$. Series II.

Fig. 2. As above, but solutions changed once only. Series II.

Fig. 3. As above, but solutions never changed. Series II.

Fig. 4. Photograph showing the growth of wheat-plants in water cultures when solntions were frequently renewed. Concentration of solutions, $\mathrm{N}, \mathrm{N} / 5, \mathrm{~N} / 1 \mathrm{O}, \mathrm{N} / 20$. 
Annals of Botany,

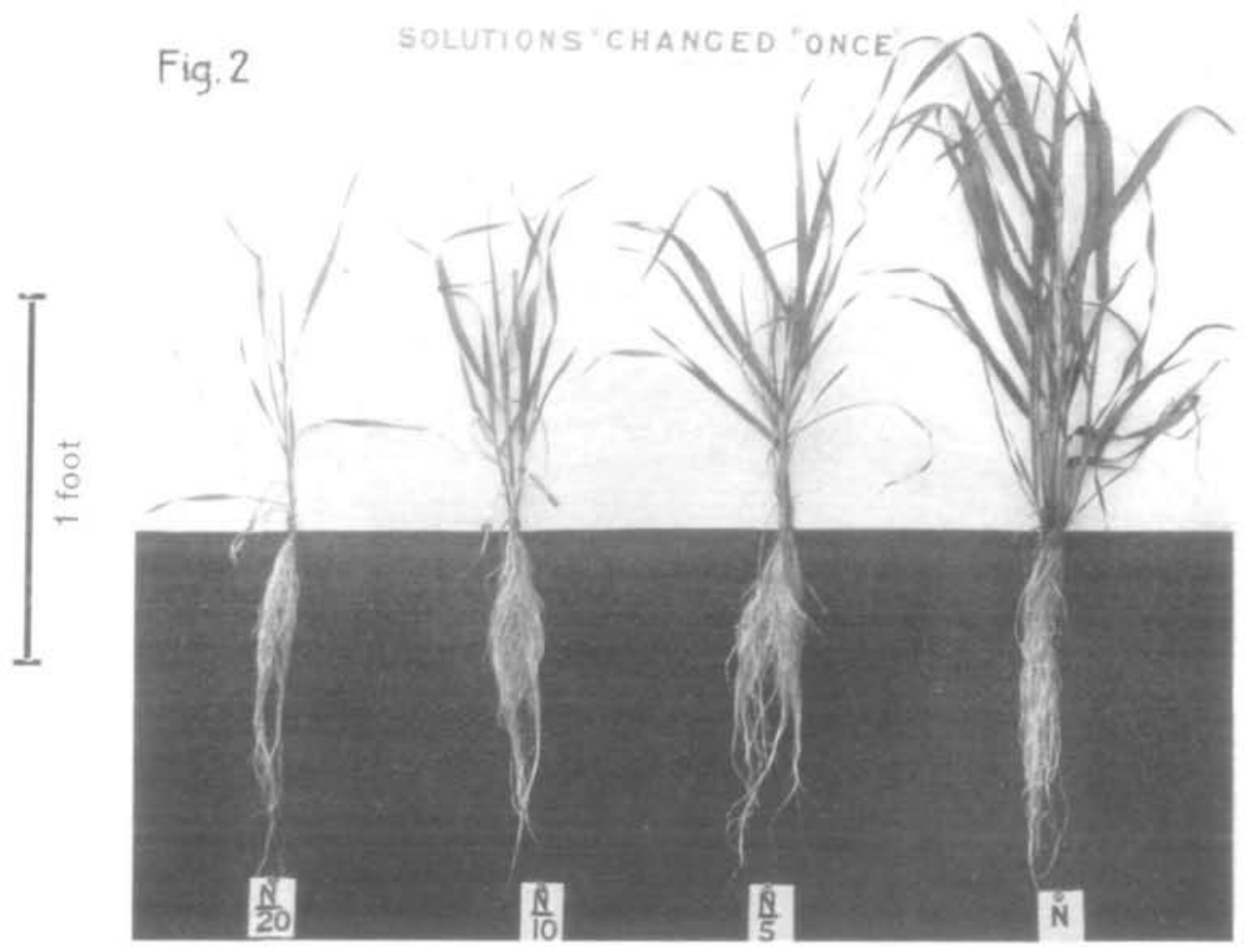

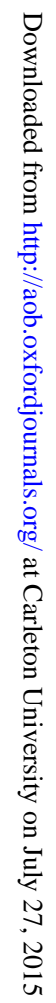

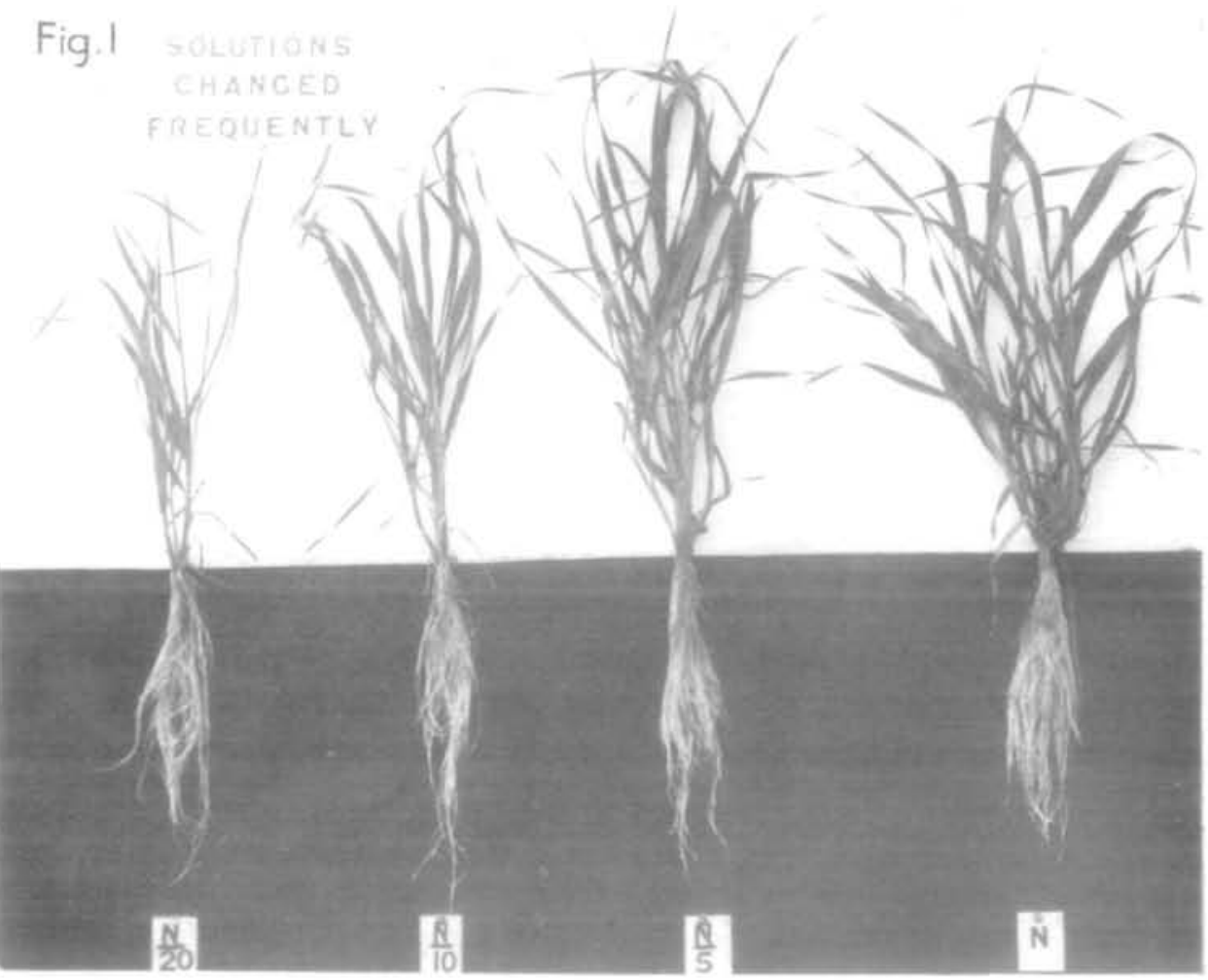

BRENCHLEY - WATER CULTURES. 
Vol. XXX, Pl. II.

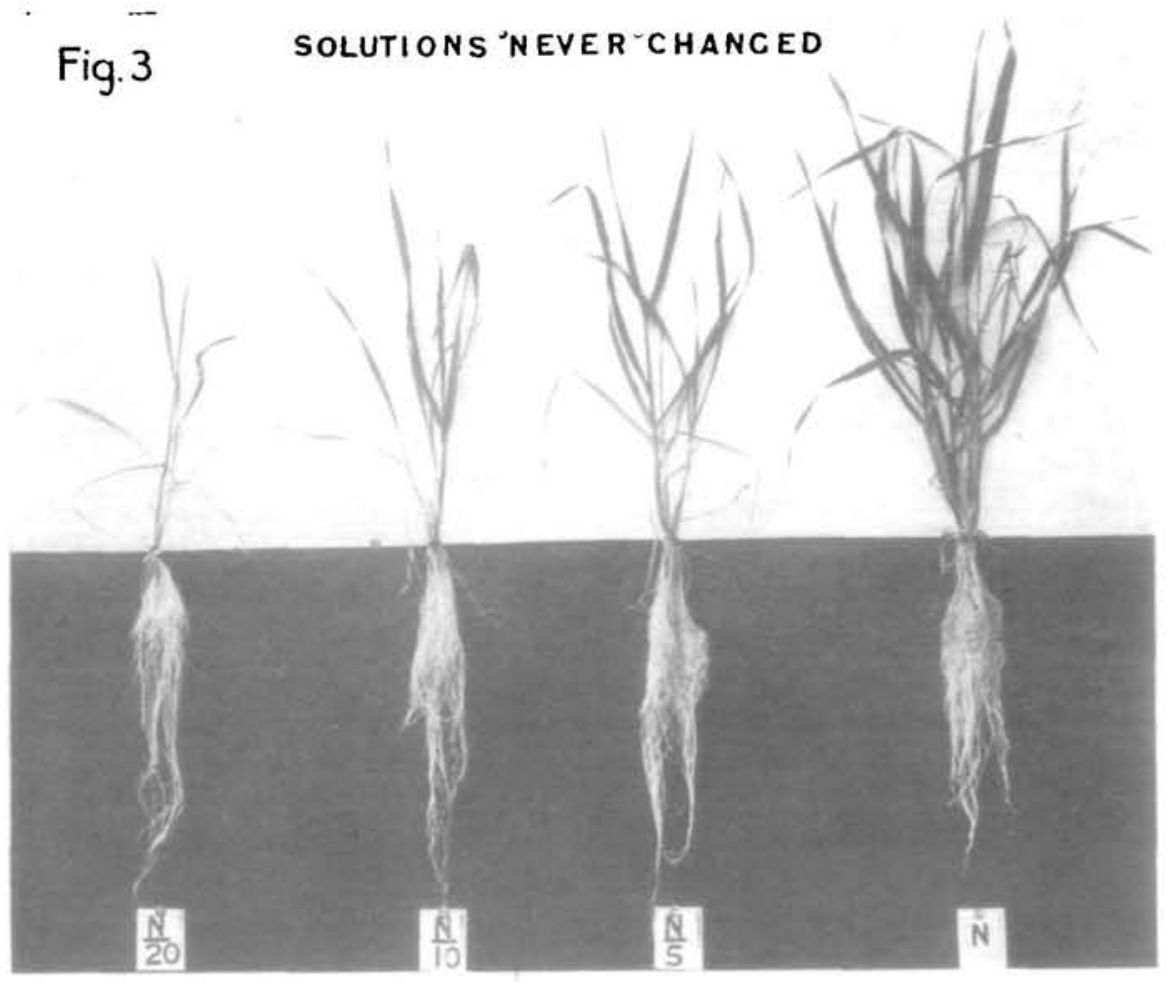

Fig. 4

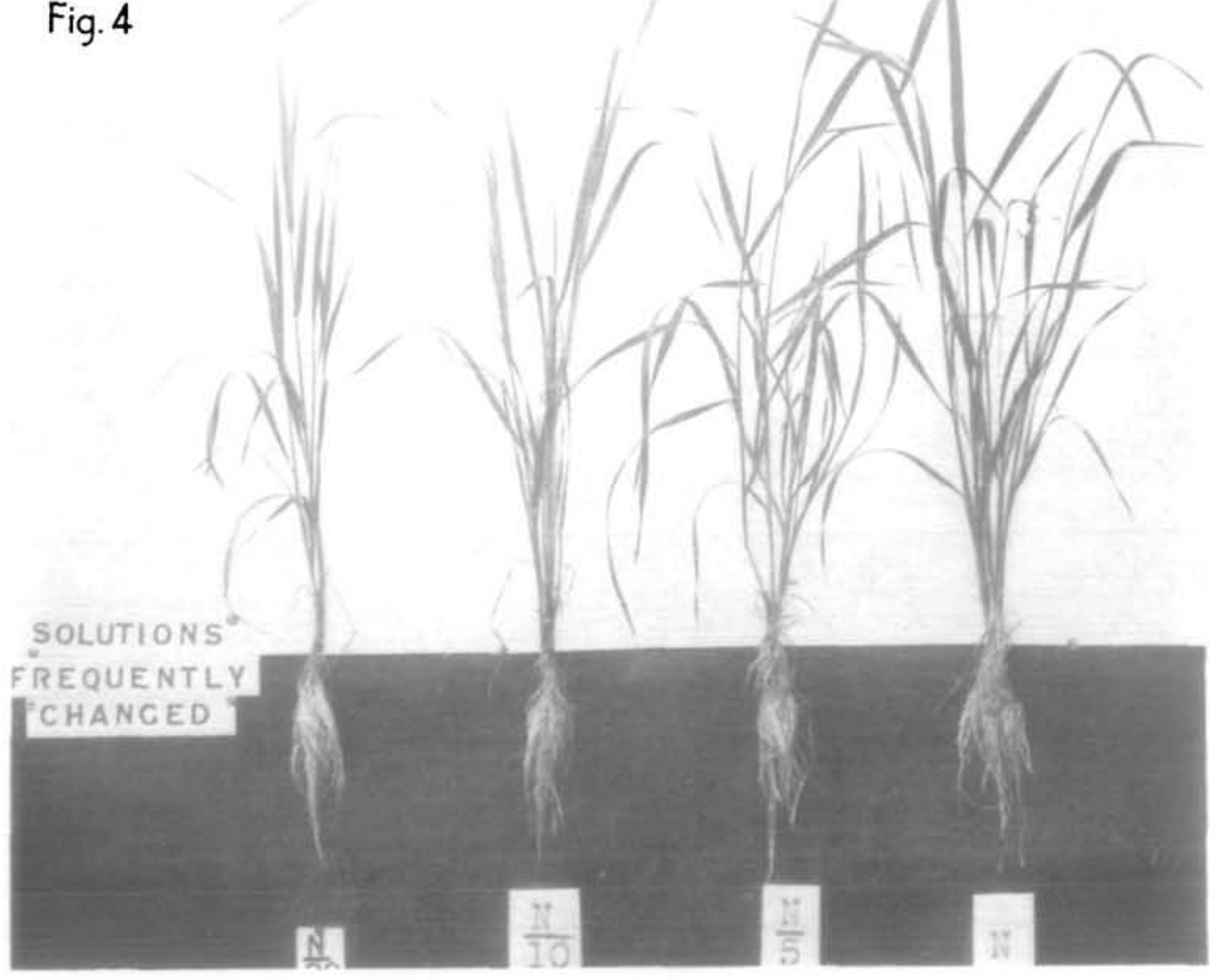

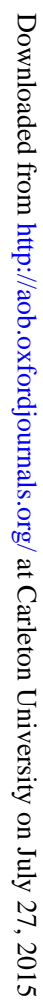

